PETER KRIEGER

\title{
El ritual de la serpiente Reflexiones sobre la actualidad de Aby Warburg, en torno a la traducción al español de su libro Schlangenritual. Ein Reisebericht
}

Goethes Zeit erwartete noch, daß Kunstwerke: "aufregen und nutzen". Solche Zeiten dürften wiederkommen. ${ }^{\mathrm{I}}$

A Biografía Intelectual de Aby Moritz Warburg destaca en las humanidades del siglo xx por su efecto inspirador a largo plazo. Su obra misma no es muy amplia, ${ }^{2}$ y en gran parte la componen fragmentos o textos

I. Aby Warburg, "Die Wandbilder im hamburgischen Rathaussaal” (I9IO), en Bibliothek Warburg (ed.), A. Warburg. Gesammelte Schriften, Leipzig/Berlín, Teuber, 1932, vol. I, p. 587; traducción libre al español (por Peter Krieger): "En el tiempo de Goethe todavía se esperaba que las obras de arte 'inspiren y sean útiles'. Aquellos tiempos pueden regresar”. Agradezco a Jaime Cuadriello, Renato González Mello, Rita Eder, Fausto Ramírez, Dúrdica Šégota y, last but not least, Ana Garduño por sus comentarios y críticas a este texto.

2. A partir de 1998, un equipo de investigadores conformado por Horst Bredekamp, Michael Diers, Kurt W. Forster, Nicholas Mann, Salvatore Settis y Martin Warnke edita las obras completas de Aby Warburg en la editorial Akademie Verlag de Berlín. Una primera selección de los textos clave de Warburg corrió a cargo de Dieter Wuttke (ed.), Aby Warburg. Ausgewählte Schriften und Würdigungen, 3a. ed., Baden-Baden, Valentin Koerner, 1992. Según una sospecha de Elias Bickermann, se requieren amplios conocimientos para escribir un libro, pero sólo ignorancia para publicar- 
DOI: http://dx.doi.org/10.22201/iie.18703062e.2006.88.2208

240

PETER KRIEGER

inconclusos como el atlas Mnemosyne, 3 proyecto que pretendió entender la codificación de gestos visuales en diferentes contextos históricos y culturales. A este proyecto de investigación se inscribió también la ponencia sobre "el ritual de la serpiente" que Warburg, bajo el título "Bilder aus dem Gebiet der Pueblo-Indianer" (imágenes del territorio de los indios "pueblo"), impartió el 2r de abril de I923 en la lujosa clínica psiquiátrica del doctor Binswanger en Kreuzlingen. ${ }^{4}$

Anteriormente —en enero, febrero y marzo de 1897-, Warburg ya había presentado sus cincuenta imágenes fotográficas del ritual de la serpiente y sus contextos topográficos a un público interesado: miembros de las asociaciones de fotógrafos amateurs en Hamburgo y Berlín. Después de la muerte del autor, su colaborador Fritz Saxl en 1930, leyó esta ponencia a los participantes de un congreso de americanistas en Hamburgo. Finalmente, en 1938, el Annual Report del Warburg Institute de Londres publicó ese texto, con modificaciones según los apuntes de Warburg mismo y correcciones de su colaboradora Gertrud Bing, con el título "A Lecture on Serpent Ritual", 5 texto decisivo para una edición

lo. Aby Warburg no tuvo esta ignorancia, pues sólo publicó 350 páginas durante su vida, mientras su escritos inéditos llenarían toda una habitación. Véase Roland Kany, "Schon die Mitwelt versetzte Aby Warburg unter die Wandelsterne. Am Firmament der Kulturwissenschaft bleibt er weiterhin beweglich. Konstellationen einer Wirkungsgeschichte”, Frankfurter Allgemeine Zeitung, II de marzo de 1999.

3. Martin Warnke y Claudia Brink (eds.), Aby Warburg. Der Bilderatlas Mnemosyne (Gesammelte Schriften, Studienausgabe, Band II.I), Berlín, Akademie Verlag, 200o. Dorothée Bauerle, "Gespenstergeschichte für ganz Erwachsene". Ein Kommentar zu Aby Warburgs Bilderatlas Mnemosyne, Münster, Lit, 1988.

4. Sobre la complicada historia editorial del Schlangenritual, véase Friederike Janshen, "Spurenlesen”, en Silvia Baumgart, Gotling Birkle et al. (eds.), Denkräume zwischen Kunst und Wissenschaft / 5. Kunsthistorikerinnentagung in Hamburg I99I, Berlín, Reimer, I993, pp. 88-9I. Michael Diers, en su artículo "Warburg für Kinder”, Frankfurter Allgemeine Zeitung, 27 de enero de 1999, informa que Aby Warburg y su colaborador Fritz Saxl publicaron, anónimamente, un breve reportaje sobre el ritual de la serpiente en la revista para jóvenes Jugend Insel. Zeitschrift für Jungen und Mädel, editado por Else Hildebrandt, núm. IV, 1926. Según Diers, es una "miniatura etnográfica con fines didácticos”, hasta ahora omitida en la investigación sobre Warburg. Véase también la reseña de Dirk Schümer en Frankfurter Allgemeine Zeitung, 27 de febrero de I999, sobre la exposición de I4I fotografías del viaje de Warburg a los pueblos indios, en el desierto oeste de Santa Fe, Nuevo México, EUA, en el Altonaer Museum de Hamburgo, en 1999, con el catálogo de esta exposición, editado por Benedetta Cestelli Guidi y Nicholas Mann, Grenzerweiterungen. Aby Warburg in Amerika I895-1896, Hamburgo/Londres, Dölling und Galitz/Warburg Institute, 1999.

5. Aby Warburg, "A Lecture on Serpent Ritual”, Journal of the Warburg Institute, II, 1938-I939, pp. 222-292 (traducción al inglés de W.F. Mainland). 
italiana de 1984 y la reedición alemana de 1988, que en 2004 una editorial mexicana publicó en español con el título El ritual de la serpiente. ${ }^{6}$

En estas reflexiones no me dedicaré primordialmente a la ubicación histórica y filológica del texto sobre la serpiente, porque el "epílogo" de Ulrich Raulff proporciona esta necesaria información al lector; 7 tampoco quiero profundizar demasiado en la biografía de Warburg, pues esa labor ha sido realizada con minuciosidad y brillantez por Ernst Gombrich ${ }^{8}$ y recientemente, con mucho material aunque menor puntualidad, por Georges Didi-Huberman; ${ }^{9}$ en cambio, perfilo algunos parámetros del pensamiento de Aby Warburg que posiblemente ayuden a entender otras dimensiones de este texto póstumo - publicado sin autorización de Warburg- ${ }^{\mathrm{io}}$ sobre el Schlangenritual, ahora disponible en español.

Después de su muerte, hace 75 años, Aby Warburg se convirtió gradualmente en una figura clave para la reforma de la historia del arte hacia la historia cultural y la ciencia de la imagen (Bildwissenschaft). El instrumento para esta transformación de una disciplina anteriormente reducida a la clasificación de estilos fue la biblioteca de ciencias culturales que Warburg estableció en su casa particular, en la ciudad de Hamburgo. ${ }^{\text {II }}$ Aby M. Warburg fue el hijo mayor de una familia judía de banqueros y, según las tradiciones familiares, fue designado para diri-

6. Aby Warburg, El ritual de la serpiente, Joaquín Etorena Homaeche (trad.), México, Sexto Piso, 2004 (Ia. ed. en alemán Schlangenritual. Ein Reisebericht, Berlín, Wagenbach, 1988).

7. Ulrich Raulff, "Epílogo", en ibid., pp. 69-II4.

8. Ernst H. Gombrich, Aby Warburg. Eine intelektuelle Biographie, Frankfurt am Main, Suhrkamp, I984.

9. Georges Didi-Huberman, L'image survivante. Histoire de l'art et temps des fantômes selon Aby Warburg, París, Minuit, 2002; véanse las reseñas de Horst Günter, "Kulturwissenschaft oder Geistergeschichte? Georges Didi-Huberman über Aby Warburg”, Neue Zürcher Zeitung, Is de marzo de 2003, y de Werner Hofmann, "Pathosformeln eines Erlösungssuchers. Der große Wurf: Georges Didi-Huberman kongeniale Biographie des einverleibenden Aby Warburg", Frankfurter Allgemeine Zeitung, 9 de septiembre de 2002; Hofmann destaca la bibliografía acumulada de más de 900 títulos como non plus ultra para las investigaciones actuales sobre Warburg.

Io. Véase la carta de Warburg a su colaborador Fritz Saxl, del 26 de abril de 1923, traducida y publicada en las páginas 67 y 68 de El ritual de la serpiente.

II. Michael Diers (ed.), Porträt aus Büchern. Bibliothek Warburg und Warburg Institute (Kleine Schriften des Warburg-Archivs Heft I), Hamburg, Dölling und Galitz Verlag, I993. HansMichael Schäfer presentó un estudio sobre los contextos bibliotecológicos y biográficos de la KBW, Die Kulturwissenschaftliche Bibliothek Warburg. Geschichte und Persönlichkeiten des Bibliothek Warburg mit Berücksichtigung der Bibliothekslandschaft und der Stadtsituation der Freie und Hansestadt Hamburg zu Beginn des 20. Jahrhunderts, Berlín, Lenos Verlag, 2004. 
gir los negocios del banco Warburg. ${ }^{12}$ Empero, como no le interesó el manejo financiero, cedió su derecho de primogénito a su hermano menor, con la condición de que él le comprara cada libro que deseara a lo largo de su vida. Lo que a primera vista pareció ser un pacto favorable para el hermano menor, paso a paso se convirtió en un trueque desequilibrado, porque Aby, a partir de 1903, tuvo la firme vocación de construir una de las bibliotecas particulares más completas en las ciencias culturales de su tiempo. Incluso, en 1925 comisionó la construcción de un edificio especial para su biblioteca creciente, que contó con las instalaciones más avanzadas de la época para la investigación en las humanidades. ${ }^{13}$

La Kulturwissenschaftliche Bibliothek Warburg ( $\mathrm{kBW}$ ), Biblioteca de Ciencias Culturales Warburg, en Hamburgo, atrajo a los intelectuales destacados de su tiempo, entre ellos al filósofo Ernst Cassirer y al historiador del arte Erwin Panofsky, entonces catedrático de la Universidad de Hamburgo. Como en las otras áreas de la sociedad, también para las humanidades, y especialmente para este proyecto, la dictadura nazi trajo consecuencias fatales. Bajo la presión fascista, los colaboradores de la Biblioteca, ayudados por algunos funcionarios del ayuntamiento de Hamburgo, lograron en 1933 transferir la Biblioteca — con sus 60000 volúmenes- a Londres, donde se fundó el Warburg Institute, ${ }^{\mathrm{I4}}$ que cuadruplicó ese fondo original de libros y revistas.

Gracias a la iniciativa persistente de Martin Warnke, ${ }^{15}$ profesor emérito de la Universidad de Hamburgo, durante las últimas tres décadas del siglo pasado, se reactivó la herencia intelectual de Warburg en su lugar de origen y en 1995 se reabrió la Casa Warburg (Warburg Haus) ${ }^{16}$ como centro de investigación interdisciplinario sobre la imagen, con un nuevo fondo, en estrecha colaboración

I2. Ron Chernov, The Warburgs. The Twentieth-Century Odyssey of a Remarkable Jewish Family, Nueva York, Random House, 1993 (edición en alemán: Die Warburgs. Odyssee einer Familie, München, втв Goldmann, 1996); Eckart Kleßmann, M. Warburg \& Co. Geschichte eines Bankhauses, Hamburgo, Dölling und Galitz, 1999.

I3. Tilman von Stockhausen, Die Kulturwissenschaftliche Bibliothek Warburg: Architektur, Einrichtung und Organisation, Hamburgo, Dölling und Galitz, 1992.

14. The Warburg Institute, University of London, www.sas.ac.uk/Warburg.

I5. Véase Werner Hofmann, Georg Syamken, Martin Warnke (eds.), Die Menschenrechte des Auges. Über Aby Warburg, Frankfurt am Main, Europäischen Verlagsanstalt, 1980. Horst Bredekamp, Michael Diers y Charlotte Schoell-Glass (eds.), Aby Warburg. Akten des internationalen Symposions Hamburg I99o (Schriften des Warburg-Archivs im Kunstgeschichtlichen Seminar der Universität Hamburg Band I), Berlín, Akademie-Verlag, I99ı.

I6. www.warburg-haus.hamburg.de. 
con Londres. ${ }^{17}$ A partir de los años noventa, incluso empezó un verdadero boom warburgiano, primero en Alemania y después, por medio de traducciones del alemán a otros idiomas, también en Estados Unidos, Inglaterra, Francia e Italia.

En México, el Instituto de Investigaciones Estéticas promovió el pensamiento de Warburg a partir del XXII Coloquio Internacional de Historia del Arte sobre el tema "(In)Disciplinas: estética e historia del arte en el cruce de los discursos" ${ }^{18}$ cuyas memorias recogen algunos textos que no sólo recuperan la memoria de Warburg, sino también perfilan el potencial futuro de esta estimulante herencia intelectual. También la serie de exposiciones realizadas en el Munal con el título Los pinceles de la historia refleja el espíritu de este intelectual sobresaliente. ${ }^{19}$

No obstante, a todos los interesados en el pensamiento warburgiano hay que advertirles que Aby Warburg no dejó una estricta metodología de la investigación sobre la imagen. Al contrario, en primer lugar sembró inquietudes sobre los sentidos de la imagen, y nos enseñó uno, entre muchos otros caminos epistemológicos, para acercarnos a las construcciones visuales y su poder. Esto no es una desventaja, porque el estímulo que proporciona el fragmento del pensamiento deja incluso más libertades para la creatividad intelectual frente a la imagen que una "metodología" estricta, como la conocemos del esquema tricótomo de la iconología según Panofsky.

Menciono este caso porque algunas publicaciones recientes, basadas en la herencia de Warburg, corren un peligro similar. Entre los intelectuales está en boga hablar de Warburg, pero de hecho, no todos los que nombran a este

17. Peter Krieger, "Las posibilidades abiertas de Aby Warburg", en XXII Coloquio Internacional de Historia del Arte. (In)Disciplinas: estética e historia del arte en el cruce de los discursos, Lucero Enríquez (ed.), México, Universidad Nacional Autónoma de México-Instituto de Investigaciones Estéticas, 1999, pp. 26I-28I. Véase también Karen Michels, "Vergessen und Erinnern. Zum 'Nachleben' Aby Warburgs in Hamburg”, en Robert Galitz y Brita Reimers (eds.), Aby M. Warburg, "Ekstatische Nymphe... trauernder Flußgott". Porträt eines Gelehrten, Hamburgo, Dölling und Galitz Verlag, 1995, pp. 228-240.

I8. Enríquez (ed.), op. cit.

19. Véase especialmente el tomo IV de esta serie: Renato González Mello (ed.), Los pinceles de la historia. La arqueología del régimen. I9I0-I955, México, Museo Nacional de Arte/Instituto Nacional de Bellas Artes/Universidad Nacional Autónoma de México-Instituto de Investigaciones Estéticas, 2003. Se está planeando una colaboración de este proyecto con la Warburg Haus de Hamburgo; concretamente, la integración de este fondo visual a la Warburg Electronic Library (WEL), dirección www.sts.tu-harburg.de/projects/WEL/entry.htm; sobre este proyecto digital véase Matthias Bruhn, “The Warburg Electronic Library in Hamburg: A Digital Index of Political Iconography”, en Visual Resources, vol. XV, 1999, pp. 405-423. 
personaje conocen bien su obra ni entienden su mensaje; se trata de un efecto comparable a la recepción de Walter Benjamin, otro pensador del siglo xx que dejó una obra fragmentada con gran potencial de inspiración. ${ }^{20}$ Abundan los autores que utilizan una cita inteligente de Benjamin, sin profundizar en su complejo pensamiento.

La autonomización de aquella industria intelectual, atractiva tanto para autores vanidosos como para editoriales comerciales, es aun más problemática en el caso de Warburg, porque él sólo publicó una muy pequeña parte de sus escritos, y por ello, como resume Roland Kany en una reseña de la mercadotecnia neowarburgiana: "Donde no hay textos, gobiernan los fantasmas." 21 Escasez y fragmentación de una producción intelectual, por un lado, y brillantez por el otro, generaron un atractivo, especialmente para los intelectuales posmodernos, que sustituyen la reflexión sistemática por una libre flotación de referencias y citas. En estos contextos académicos internacionales, un Warburg fragmentado y refriteado fácilmente se convirtió en un artículo de moda, expuesto en los mercados intelectuales; aún más, sirvió como modelo para la investigación interdisciplinaria, impuesta por las administraciones académicas en la actualidad.

Según un esquema analítico de Jan Assmann, la obra de Warburg incluso cayó en la trampa de la "canonización", que reorganiza la memoria cultural en tiempos de crisis intelectuales colectivas y, concretamente, altera la esencia del pensamiento preservado. La canonización de Warburg se organizó en dos pasos: primero, la distancia creciente respecto al texto "original", en este caso sobre el ritual de la serpiente, se compensa a través de reformulaciones, modificaciones. Segundo, el texto original sólo es accesible por un metatexto, un comentario, lo que en nuestro caso significó la Biografía intelectual de Warburg, escrita por Ernst H. Gombrich a finales de los años setenta, o las ediciones, simposios y exposiciones de 1979, en torno a la conmemoración de los cincuenta años de la muerte de Warburg. A partir de esto, el sujeto canonizado se convierte en objeto

20. Sobre las similitudes entre Warburg y Benjamin, véase Cornelia Zumbusch, Wissenschaft in Bildern. Symbol und didaktisches Bild in Aby Warburgs Mnemosyne-Atlas und Walter Benjamins Passagen-Werk, Berlín, Akademie-Verlag, 2004, donde la autora explica el nuevo concepto historiográfico más ilustrativo de los dos pensadores, en el caso de Warburg enfocado a la simbología visual del Renacimiento y, en el de Benjamin, concentrado en los símiles dialécticos para la realidad social en las ciudades del siglo XIX.

2I. Kany, op. cit. 
de culto, lo que, de hecho, contradice a la personalidad modesta de Warburg y sus colaboradores o sucesores, como Gombrich. ${ }^{22}$

Es grato mencionar estos peligros mercadotécnicos de nuestra disciplina, en un momento caracterizado por el creciente interés general en cuestiones de cultura visual, cuando Warburg, de cierta manera, aventaja a Benjamin. Un pensamiento complejo del pasado requiere una consideración sutil y no una copia simplificada.

La lectura del texto aquí tratado, sobre un ritual y su imaginario, seduce sin duda, a muchos lectores. Posiblemente, los contemporáneos de una civilización hipermodernizada encontrarán en un ensayo sobre la codificación simbólica de las fuerzas naturales una plusvalía de compensación. Cuando, al final de su texto, Warburg lamenta que la tecnología moderna destruye los espacios para la contemplación, inicia un basso continuo de la crítica cultural de lo moderno a lo largo del siglo xx, que llega hasta su tergiversación en la industria mental del esoterismo. Pero eso, según mi punto de vista, no es la esencia de los textos warburgianos lo que importa, sino el descubrimiento del potencial epistemológico de la imagen.

En este sentido, no es importante si la imagen tratada es obra de arte u otro tipo de documento visual. Por supuesto, la obra de arte se produce a través de una densificación estética de un mensaje simbólico; pero también cualquier otro tipo de imagen emite una comunicación visual que requiere un trabajo sutil de interpretación. Ambos tipos de imágenes son documentos de una cultura, de creencias, estrategias económicas y políticas. El diseño de una lata, como una vez dijo Ernst Gombrich, ${ }^{23}$ también expresa una iconografía que permite analizar los valores visuales de su tiempo y lugar de procedencia.

"Soy historiador de la imagen (Bildhistoriker), no historiador del arte", anotó Aby Warburg en su diario, todavía inédito, de 1917, y ese aspecto es básico para el concepto intelectual de su texto El ritual de la serpiente, donde un gran espectro de diferentes imágenes - desde dibujos medievales hasta esbozos amateurs y fotografías cotidianas realizadas por el mismo Warburg con una cámara

22. Sobre los peligros de la glorificación de un intelectual, véase Peter Krieger, "Ernst Hans Gombrich-sustentabilidad del pensamiento", Anales del Instituto de Investigaciones Estéticas, núm. 79, 200I, pp. 209-217.

23. Ernst H. Gombrich, Arte e ilusión. Estudio sobre la psicología de la representación pictórica, Barcelona, GG, 1979 (edición original en inglés: Art and Illusion. A Study in the Psychology of Pictorial Representation, Oxford, Phaidon, 1960), p. 22: "Vemos aspectos de la realidad representados en la pantalla de televisión y en el cine, en sellos de correo y en latas de conservas." 
Kodak - abarca la complejidad de la temática. Warburg hizo suya la inspiración de su colega vienés Alois Riegl, quien aun en los artefactos más pobres detectó las profundas transformaciones culturales a lo largo de la historia. Para la definición warburgiana de una "Ciencia de la cultura", esta ampliación del fondo de objetos estudiados fue fundamental. En sus escritos no sólo analizó las obras de arte canonizadas, sino también libelos ilustrados, sellos, escenografías efímeras y otros tipos de documentos visuales con distribución masiva. La cultura no se configura únicamente en el elevado nivel de la obra de arte, sino despliega su potencial —crítico o afirmativo— también en un sinnúmero de otras construcciones visuales.

Como muchos otros colegas contemporáneos en Alemania a fines del siglo XIX, Aby Warburg enfocó primero sus estudios en el mundo pictórico del Renacimiento italiano, una fase de interesantes cruces entre las iconografías cristianas y paganas-antiguas. Terminó su tesis doctoral sobre Sandro Botticelli en I89I y la publicó en I893. Durante los siguientes dos años se dedicó a estudios posdoctorales en los archivos de Florencia, fortaleciendo su carrera de historiador del arte renacentista. Pero en 1895 se atrevió a reorientar su camino intelectual. Cansado del mundo visual de la Vieja Europa, realizó — con un pretexto familiar - un viaje a Estados Unidos, durante sólo unas semanas, entre I895 y I896, buscando el diálogo con las iconografías antiguas extraeuropeas. Ulrich Raulff relata en su "epílogo" el contexto biográfico de esta decisión. No menciona que la selección del objeto de estudio, los “indios” estadounidenses, surgió a través de un impulso psíquico en la infancia de Aby Warburg. Durante unas vacaciones en Ischl, Austria, el joven Aby pidió prestadas de la biblioteca local unas novelas de indios. La lectura le ayudó a escapar de una difícil realidad, en la que él y sus hermanos tenían que repetir las monótonas oraciones judías para la madre gravemente enferma. ${ }^{24}$

Ese motivo psíquico anticipa el afán de Warburg de exponerse al contraste (de culturas) como motor del conocimiento. De ahí surgió su interés en el cru-

24. Karl Königseder, “Warburg im 'Bellevue”, en Robert Galitz y Brita Reimers (eds.), Aby M. Warburg. "Ekstatische Nymphe... trauernder Flußgott... ”, op. cit., pp. 92-93; cita de Warburg, quien narra su memoria correspondiente a 1874: "Diese Indianer-Romane habe ich in ganzen Haufen damals konsumiert und dadurch offenbar das Mittel gefunden, mich von einer erschütternde Gegenwart, die mich wehrlos machte, abzuziehen”. Traducción libre al español (por Peter Krieger): "En esos tiempos consumí en grandes cantidades esas novelas de indios y de este modo encontré aparentemente el recurso para escapar de una terrible realidad, que me hacía sentir inerme." 
ce de culturas a través de códigos visuales. Las investigaciones del Bureau of American Ethnology en la Smithsonian Institution de Washington, D.C., ${ }^{25}$ le apoyaron en su investigación transcultural sobre la imagen y su función como expresión de la memoria social. ${ }^{26}$

Como toda cultura depende de una capacidad mnemotécnica, no sólo la imagen, sino también su historiador cumple una función social, en su intento de preservar y explicar la memoria de pueblos, regiones y ciudades; Warburg legitimó sus labores con esta función, y la explicó por medio de su ponencia "El ritual de la serpiente", que de hecho rescata los reductos de una cultura periférica, olvidada, que ya en los tiempos de Warburg se enfrentó a la amenaza de la alienación por los estándares globales occidentales.

No obstante, Warburg nunca elaboró su idea de memoria social como teoría coherente. Peor aún, como advirtió Ernst Gombrich, sus lecturas de Carl Gustav Jung y otros psicólogos le llevaron a adoptar, sin distancia crítica, muchos clichés de la presunta teoría de la razas, alrededor de 1900. De esta manera, su concepto de una antropología visual se basa en pilares dudosos, hoy en día rebasados. Pero esta advertencia no minimiza los logros de Warburg, porque si descontamos esta psicologización problemática de la lectura de imágenes —especialmente en su última obra Mnemosyne - ${ }^{27}$ queda un modelo de historia cultural que activa y relaciona el potencial imaginativo de diferentes culturas, en este caso la india-estadounidense y la clásica-occidental.

En el libro tratado, el topos central es la serpiente, un animal que provoca ansiedades y simboliza la muerte en diversas culturas del mundo. Warburg no pretendió homogeneizar ni aun "globalizar" un símbolo con diferentes articulaciones y usos, sino perfilar y comparar las diferentes configuraciones visuales en que se expresa ese terror. La imagen de la serpiente, desde la escultura de Lao-

25. El estímulo para conocer a los "pueblos" lo recibió Warburg a través de la recomendación, por parte de los investigadores de la Smithsonian Institution, del libro de Gustaf Erik Adolf Nordenskjöld, The Cliff Dwellers of the Mesa Verde, Southwestern Colorado, Their Pottery and Implements, Nueva York, 1973 (reimpresión de la ed. de 1893).

26. Carlo Ginzburg, "Kunst und soziales Gedächtnis. Die Warburg-Tradition", en Spurensicherungen. Über verborgene Geschichte, Kunst und soziales Gedüchtnis, München, DTV, I988, pp. I49-233. Kurt W. Forster, "Aby Warburg's History of Art: Collective Memory and the Social Meditation of Images", Daedalus, Journal of the American Academy of Arts and Sciences, núm. I05, 1976, pp. 169-176.

27. Gombrich critica que la idea de la "expresión" se basa en la biología y en la psicología social, y, por ello, implica el problema latente de la sobreinterpretación de la imagen, incluso del peligro de la banalización. Véase Gombrich, op. cit., pp. 330-33I. 
coonte hasta la danza del pueblo de Oraibi, cumple una función catártica para la memoria social: con sus herramientas y capacitaciones visuales, una comunidad busca "digerir" y expresar visualmente sus arcaicas experiencias.

Contradice esta idea de investigación la codificación heterogénea de la serpiente, no sólo de manera negativa como la seductora serpiente Tiamat de Babilonia, sino también la serpiente que circunda el bastón de Asclepio (en el siglo $\mathrm{v}$ a.C.), símbolo de la fuerza domesticada para usos médicos. Warburg mismo integra estas contradicciones en su argumentación, precisamente para no caer en la trampa epistemológica de la simplificación. Tampoco centraliza el topos de la serpiente según los modelos discursivos de la Biblia, donde aparece como medio de aquel pecado que acarrea la expulsión del paraíso. Lo que distingue a la investigación de Warburg es la comparación de diferentes culturas, sus mitologías e imaginarios.

Más allá de la psicologización problemática en su discurso, Warburg fundó sus exploraciones de la serpiente en la indagación racional, distante - y no dogmática- sobre las religiones. Rastrea la memoria cultural de la imagen hasta sus estratos espirituales y explica las funciones religiosas de los imaginarios. Esto, en su tiempo, fue una verdadera innovación en la historia del arte. ${ }^{28}$ Probablemente, el interés por la cercana relación de los cultos religiosos y la producción artística, sus efectos, sus tabúes, surgió de su discrepancia con la práctica religiosa de la familia Warburg, el judaísmo, una religión con prohibiciones icónicas.

Es la diferencia la que estimula la introspección y la comparación, lo que amplía el panorama intelectual. La comparación intercultural del imaginario de la serpiente no sirvió a Warburg para plantear una presunta superioridad de una cultura o una religión sobre la otra; al contrario, en su texto descartó implícitamente los neocolonialismos y monopolizaciones teológicas de su tiempo. En lugar de instalar una competencia falsa de culturas o religiones, la comparación le sirvió como instrumento científico para entender la historia funcional de la imagen en contextos rituales. Warburg quería comprender cómo la energía mental de una cultura o una creencia generan imaginarios afectivos.

28. Según Kany, los estudios de Warburg sobre Botticelli primordialmente fueron innovadores por su inclusión de las ciencias de las religiones (Religionswissenschaft), mientras otros tópicos de su investigación ya estaban explorados, concretamente los paralelos entre imágenes y textos (por Julius Meyer), el programa iconográfico (por Eugène Müntz), la continuidad (Nachleben) de motivos antiguos (por Anton Springer), el patrocinio del arte renacentista (por August Schmarsow), la importancia de las fiestas y su estética efímera (por Jacob Burckhardt) y la representación pictórica del movimiento (por Robert Vischer). 
Para esta tarea, Warburg entrenó su capacidad de ver. Aprovechó y extendió consecuentemente su educación en historia del arte. Cuando visitó los pueblos indios en Nuevo México, sin entender sus múltiples dialectos, aun sin disponer de un traductor capacitado, recurrió a lo básico de su disciplina: el análisis y la comparación de construcciones visuales. Para "leer" imágenes y detectar sus fórmulas visuales, sus sentidos, sus usos, Warburg desarrolló un eficaz aparato de investigación que incluso le permitió elaborar esta ponencia sobre la serpiente: su fichero de motivos visuales, ordenado mediante términos clave. En tablas negras colgó, bajo un término, diferentes imágenes con el mismo motivo iconográfico; por ejemplo: imágenes de la serpiente en representaciones visuales de Roma antigua o América actual. Los términos, que definían características formales o gestos humanos, ordenaban los imaginarios pluridimensionales, aun ilógicos.

Entre la percepción visual de la imagen y la elaboración terminológica para capturar la impresión estética, surgió, de esta manera, un "espacio de reflexión" (Denkraum), un espacio entre estímulo y reacción, donde se ubica la investigación sobre la imagen; también un espacio para convertir el miedo en un motivo - como la serpiente_- en un elemento del conocimiento racional. Es lo que Warburg, poco antes de su muerte, explicó así: "Der Leidschatz der Menschheit wird humaner Besitz" (el fondo de pasiones y sufrimientos de la humanidad se convierte en propiedad humana). ${ }^{29} \mathrm{O}$, como en otra ocasión anotó en su agenda: "La lucha con el monstruo es el germen de la construcción lógica."30

No obstante, esta lucha con el potencial ilógico, descontrolable, de la imagen, le afectó profundamente. Durante años, en la clínica de Kreuzlingen, el "monstruo" aparentemente dominó al investigador y su lógica. A lo largo de sus estudios, Warburg — según Gombrich— se hipersensibilizó ante el lenguaje de los símbolos visuales, un peligro latente conocido por cada historiador del arte. En sus imaginarios archivados vio fantasmas, visiones demoniacas del tesoro visual acumulado. Los primeros signos de una sobreexcitación mental, que desembocó en esquizofrenia, ${ }^{31}$ ya se habían mostrado en 1918 , año en que

29. Vortrag vor der Hamburger Handelskammer, Warburg Institute, núm. I2.27, 1928. 30. Allgemeine Ideen 1927, Mappe mit Notizen, Warburg Institute, Manuskript núms. I2.29, Typoskript núms. IO2.I.2, IO2.I.4, p. I9.

3I. Para Georges Didi-Huberman, la esquizofrenia de Warburg es un elemento constitutivo de su pensamiento paradójico, que oscila entre ansiedades arcaicas y el espíritu clarificador de la Ilustración, motivo que determinó claramente la elaboración de El ritual de la serpiente. A nivel metodológico, Didi-Huberman constata que las rupturas de la historia afectaron la estructura 
terminó la primera guerra mundial. En 1921, Warburg tuvo que trasladarse a la mencionada clínica, donde permaneció hasta I924. Su ponencia académica sobre la serpiente reactivó la fuerza intelectual en la lucha contra monstruos y fantasmas. Y cuando el nuevo edificio de la Biblioteca de Ciencias Culturales (KBW) abrió sus puertas en 1926, el investigador aparentemente había ganado la batalla en nombre del racionalismo.

Animado por su recuperación, Warburg incluso deseaba, en el verano de 1928, viajar de nuevo y visitar los pueblos indios de Estados Unidos, pero Ludwig Binswanger, jefe de la clínica y todavía psiquiatra responsable de Aby Warburg, le prohibió la larga excursión. En lugar de esto viajó a Roma, donde trabajó, hasta su muerte en 1929, en el atlas visual Mnemosyne, que, según Kurt Forster, fue un instrumento de evocación comparable a los altares de la tribu indígena de los hopi. ${ }^{32}$

En términos más neutrales, la herencia intelectual de Aby Warburg, ${ }^{33}$ concretamente la capacitación en el entendimiento de los procesos visuales como instrumento de las prácticas sociales en diferentes culturas, es valiosa. Pocos textos como éste sobre la serpiente relacionan con tanta claridad la imagen (de la serpiente en la arena) con su simbolismo (el rayo) y su acción (la danza ritual).

Por ello, el texto breve sobre el Schlangenritual proporciona una excelente oportunidad para reflexionar sobre nuestra cultura visual, sus orígenes y sus funciones. En América, Warburg conoció una nueva manera de imaginar el mundo, muy distinta de las tradiciones europeas; pero también en otras investigaciones aprovechó el principio del antropólogo, que se mueve en su propia cultura como extranjero, con una mirada distante y analítica sobre su propia cultura visual.

Aby Warburg ofreció a sus contemporáneos y a las siguientes generaciones, hasta hoy, un modelo refrescante de las investigaciones estéticas. Además, su compromiso profundo - y costoso- con las humanidades es un modelo atractivo del mecenazgo de proyectos intelectuales, tanto en México como en otros países del mundo, donde las humanidades, medio para la ubicación del ser humano, sufren una erosión preocupante. \$

del pensamiento del historiador que sufrió esquizofrenia, un cruce interesante entre el topos histórico y su investigador.

32. Kurt W. Forster, "Warburgs Versunkenheit", en Robert Galitz y Brita Reimers (eds.), Aby M. Warburg, "Ekstatische Nymphe... trauernder Flußgott...", op. cit., p. 200.

33. En términos cuantitativos, esta herencia intelectual se comprueba en una amplia bibliografía secundaria sobre Warburg, que comprende más de 3000 títulos; véase Dieter Wuttke, $A b y M$. Warburg-Bibliographie I866 bis 1995. Werk und Wirkung. Mit Annotationen, Baden-Baden, Valentin Koerner, 1998. 